\title{
Joint energy and reserve markets: current implementations and modeling trends
}

\author{
Pablo González*, José Villar, Cristian A. Díaz, Fco. Alberto Campos \\ Institute for Research in Technology, Technical School of Engineering, Comillas Pontifical University. Madrid 28015, Spain
}

\begin{abstract}
The continuous penetration of intermittent technologies is gradually reinforcing the technical and economic importance of electricity ancillary services, which are responsible for guaranteeing the reliability and security of the power systems. Generation companies', regulating entities, system operators and other institutions (such as researchers on these fields) are more and more concerned on using market models to forecast most relevant outcomes for particular markets (such as energy and reserves cleared quantities and prices), under different simulation scenarios (such as costs or demand) and under different markets structures (such as more competitive or more oligopolistic). This paper reviews most energy and reserve markets implementations (mainly focusing on reserve types and dispatching methods), and discusses different approaches to model them. A theoretical equilibrium model for energy and reserve markets is also proposed.
\end{abstract}

\section{Keywords}

Ancillary services, cooptimization, energy and reserve markets, Nash equilibrium, oligopoly.

\section{Introduction}

In the last decades, electricity systems have been gradually evolving towards restructured structures, where generation companies (GenCos) and commercial companies make selling and buying bids in order to plan the operation of the system for the next day (see [1]). These resulting electricity markets are frequently characterized by an oligopolistic nature, and this behavior has become a crucial issue for the GenCos (see [2-4]).

Only energy auctions are not sufficient to guarantee the necessary reliability and stability of the power system (see [5 and 6]). Hence, there exist a group of commodities known as "ancillary services" in charge of this mission. Some of these services are offered in open auctions in which GenCos might be able to exercise market power. In addition, the increasing penetration of some renewable technologies, characterized by its intermittent and uncertain production (such as wind or solar) is gradually reinforcing the importance of these ancillary services for preserving the system reliability (see [1 and 7]). An example of this closed relationship between intermittent technologies and ancillary services is that many researchers include the production of such technologies in the calculation of reserve requirements (see [8-11]).

Whereas there has been much research done on energy market modeling (see [12,13]), fewer are the authors that model both energy and reserve markets (see the introduction of [14]). This might be due to the higher complexity in computation and mathematical formulation required for these models and to the small current impact of ancillary services onto the total end user tariff. For example, this impact is currently around $10 \%$ in Spain (see Fig. 1, which has been elaborated from data provided by [15]), but it is progressively

\footnotetext{
* Corresponding author.

E-mail addresses: pablo.gonzalez@iit.upcomillas.es(P.González), jose.villar@iit.upcomillas.es (J. Villar), cristian.diaz@iiit.upcomillas.es (C. A. Díaz),
}

alberto.campos@iit.upcomillas.es (F. A. Campos).

Tel: +34 915422800; Fax: +34915423176 
increasing, and it is expected to become even more significant with the ongoing integration of interruptible renewable energies into the system (in 2020, the Spanish government intends the $40 \%$ of the total electricity generation to be supplied by renewable sources [16]).

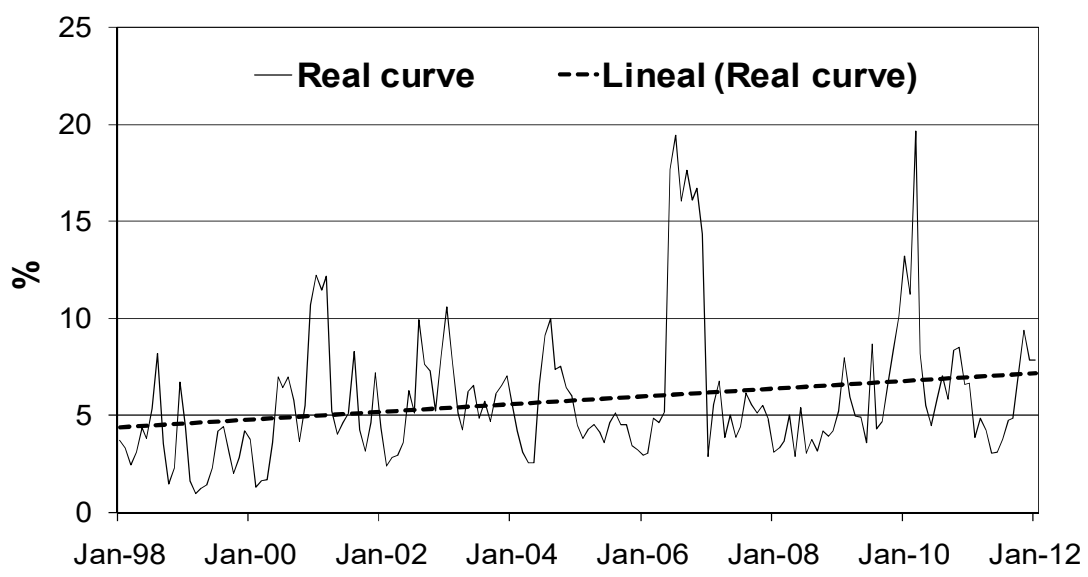

Figure 1: Monthly contribution in \% of ancillary services into the final average cost for the Spanish market (data taken from [15]).

The objective of this paper is to review most different approaches related to energy and reserve markets modeling, so as to further develop a real scale oligopolistic model integrating both commodities, meant to provide cleared energies and reserves quantities and prices.

This paper is organized as follows. Sections 2 reviews current types of technical reserves', while section 3 focuses on current energy and reserve market implementations (mainly sequential or joint dispatches approaches), over different power systems. Section 4 presents the main technical characteristics of the identified reserves types. Section 5 reviews the way researchers integrate these features into their modeling approaches, attending both to energy and reserve sequential or joint dispatches, but also considering competitive or oligopolistic market behaviors. Based on the results of previous sections, section 6 proposes a general set of energy and reserve equilibrium equations and constraints, and finally, section 7 summarizes the main conclusions.

\section{Ancillary services}

The classification of ancillary services and the mechanisms that rule their management is differently conceived among countries (see [7]). It seems clear that these services contribute to the reliability and the security of the system (see [5 and 6]). However, regulatory organisms do not always coincide in the ways to regulate these services.

For instance, the Federal Energy Regulatory Commission of the USA (FERC) groups them into six classes: scheduling; system control and dispatching service of interchanges with other control areas; reactive supply and voltage control; regulation and frequency response service; energy imbalance service and two operating reserves: spinning reserve service and supplemental reserve service [17]. Another possible scheme is proposed in the Spanish system in which ancillary services are organized into three categories: resolution of technical constraints, complementary services (divided into primary, secondary and tertiary regulation) and balancing market [18].

A general classification of ancillary services and a comparative analysis between countries' management of these has been made in [7]. This analysis shows that the existing spot markets for ancillary services refer mainly to frequency and load control services (commonly denoted by reserves). Other services such as blackstart capability or reactive power for voltage regulation will not be within the scope of this review. 
Reserves are usually classified according to their technical characteristics: responding timescale in which they must be provided, controlling mechanisms that rule their coordination and type of event they must respond to. Firstly, faster responding services are graded as higher quality ones, and can also be offered as slower ones. Secondly, reserves can be either automatically controlled or manually assigned. Automatic control can be exerted in a local range using the automatic governor of the turbines in a power plant, or in a zonal range by means of the Automatic Generation Control (AGC) that coordinates multiple generators at different power plants. Finally, reserves can respond to different types of event, as, for instance, the loss of a generator or a line, or the correction of demand, solar or wind generation forecasted errors.

\subsection{U.S.A reserves classification}

A widespread classification is described in [11,19-21]. Three groups of reserves are distinguished: regulation, spinning/non-spinning reserve and replacement reserve (also commonly known as operating or supplemental reserve).

Regulation covers the continuous fast and frequent changes in load and generation that create energy imbalances and frequency fluctuations. It is controlled by the Automatic Governor of the Turbines (AGT) and by the AGC, and must respond almost simultaneously to system load fluctuations.

Spinning, non-spinning and replacement reserves restore the generation and load balance in the event of a contingency.

Spinning reserve responds almost simultaneously (within seconds) to a contingency, but it is only required to be fully available within 10 minutes and maintained for 2 hours.

Non-spinning reserve does not require the permanent synchronization of the unit to the grid, but rapid start up and total availability must be guaranteed within 10 minutes.

Finally, replacement reserve is intended to substitute faster and more expensive reserves, so as to reduce costs and guarantee security against subsequent contingencies, and must be supplied within 30 minutes at the latest.

Table I indicates the existing reserve markets for different American operators (from [22-28]). Column 1 presents the time for which the regulation service must be maintained. In the rest of columns the responding time requirement is indicated. It is also indicated whenever the service is differently named to the column title (row 1).

Table 1: Principle frequency and load control ancillary services offered in some American markets

\begin{tabular}{|l|l|l|l|l|}
\hline Market & $\begin{array}{l}\text { Regulation and frequency } \\
\text { response (maintaining time) }\end{array}$ & $\begin{array}{l}\text { Spinning reserve } \\
\text { (responding time) }\end{array}$ & $\begin{array}{l}\text { Non spinning reserve } \\
\text { (responding time) }\end{array}$ & $\begin{array}{l}\text { Replacement reserve } \\
\text { (responding time) }\end{array}$ \\
\hline $\begin{array}{l}\text { PJM } \\
\text { [24] }\end{array}$ & $40 \mathrm{~min}$ & $10 \mathrm{~min}$, Synchronous & $\begin{array}{l}10 \mathrm{~min}, \text { Quick start } \\
\text { reserve }\end{array}$ & $10-30 \mathrm{~min}$, Supplemental \\
\hline $\begin{array}{l}\text { NYISO } \\
\text { [25] }\end{array}$ & $60 \mathrm{~min}$ & $10 \mathrm{~min}$ and $30 \mathrm{~min}$ & $10 \mathrm{~min}$ and $30 \mathrm{~min}$ & $\mathrm{~N} / \mathrm{A}$ \\
\hline $\begin{array}{l}\text { ISO-NE } \\
\text { [26] }\end{array}$ & $60 \mathrm{~min}$ & $10 \mathrm{~min}$ & $10 \mathrm{~min}$ & $30 \mathrm{~min}$ \\
\hline $\begin{array}{l}\text { CAISO } \\
\text { [22] }\end{array}$ & $60 \mathrm{~min}$ & $10 \mathrm{~min}$ & $10 \mathrm{~min}$ & N/A \\
\hline $\begin{array}{l}\text { MISO } \\
\text { [28] }\end{array}$ & $60 \mathrm{~min}$ & $10 \mathrm{~min}$ & N/A & Supplemental, $10 \mathrm{~min}$ \\
\hline $\begin{array}{l}\text { ERCOT } \\
\text { [27] }\end{array}$ & $60 \mathrm{~min}$ & $\begin{array}{l}10 \mathrm{~min}, \text { Responsive } \\
\text { reserve }\end{array}$ & $30 \mathrm{~min}$ & N/A \\
\hline
\end{tabular}



trends. Electric Power Systems Research. vol. 109, pp. 101-111, April 2014. JCR 1.749 (2014), 2.688 (2016).

\subsection{European reserves classification}

In Europe, regardless the heterogeneity within countries, references [11] and [29] relate some reserve markets by classifying them with a similar notation. Their work focuses on frequency control services, identifying three different types of reserves: primary, secondary and tertiary.

Primary reserve is provided by the AGT, and acts locally at each synchronous generator, sharing some characteristics with the USA regulation service. It responds to the speed of the rotation axis of the turbine, being an almost instantaneous service.

Secondary reserve is managed within a control area (provided by a set of generating units connected to a same AGC) and responds to frequency variations and load interchanges with other control areas, and corresponds to a combination of regulation and spinning reserve USA services. It must be supplied within seconds up to few minutes.

Finally, tertiary reserve is manually controlled and must be supplied within minutes. It is used to restitute the secondary energy that is being used for regulatory purposes. It includes non spinning and replacement reserves characteristics.

A specific example of the European scheme is the Spanish one (see [30-34]), in which primary reserve must act within 15 seconds for a frequency variation of $100 \mathrm{mHz}$ and within 30 seconds for disequilibrium under $200 \mathrm{mHz}$. Secondary reserve's responding time is the equivalent to a linear control system with a 100 seconds time constant and must be maintained for 15 minutes. Tertiary reserve must be supplied within 15 minutes and maintained for two consecutive hours. Whereas primary is a mandatory and non-remunerated service, secondary and tertiary reserves have their own separated auctions (see [30]). Secondary reserves are totally optional, but in the tertiary reserve markets, all conventional generators are obliged to offer all their tertiary capacity, but they can select their offer price (see [30]).

Based on [11], Fig. 2 shows an approximate correspondence between both schemes.

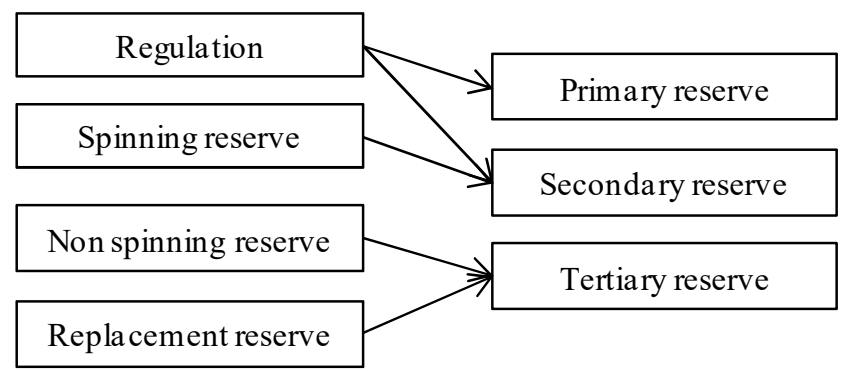

Figure 2: Comparison between American and European classification on reserves (based on [11]).

\section{Energy and reserve market implementations: Dispatching methods}

The management of electricity markets has been differently conceived all over the world, as electricity is a complex commodity that depends on difficult quantifiable aspects such as intertemporal constraints, nonconvex costs or grid technical constraints. Hence, the format of the generators' energy offers can range from the so-called simple offer (a series of quantity-price pairs per time interval) to a grayscale of more complex alternatives, in which multiple information can be declared, such as start-up and shut-down costs or ramping characteristics (see [35]). Note that in simple auctions, bids must implicitly consider complex constraints such as non liner costs or ramping limits, whereas in complex auctions, each bid is accompanied by a set of declared technical characteristics and costs.

In simple auctions, the Market Operator (MO) corresponds to the independent entity in charge of ruling the economic auction. Therefore, the MO has to be coordinated with the System Operator (SO), who is responsible for guaranteeing a safe and secure supply to the consumer. In complex auctions, the MO and the 
SO can be a same entity, which clears the market using an optimization-based algorithm (known as security constrained economic dispatch) to maximize the net social benefit (see [35]).

The multi-dimensional nature of the problem (energy and multiple reserves) leads to different alternatives to tackle the whole dispatch. Reference [36] enumerates three possible approaches: separated merit-order based dispatch, sequential dispatch and joint dispatch, being sequential and joint (this last also denominated as co-optimization) the most used (see table II).

In the merit-order based dispatch, a separate and independent merit-order stack is simultaneously planned for each product, although this approach might lead to infeasibilities for some units (see [36]).

In sequential markets, one of the commodities (typically energy) is cleared first. Once the first market is solved, (price, productions for each selling company and consumptions for each buying company determined) the agents bid in the subsequent markets, being their strategies conditioned by the results of the previous cleared ones (see [36]). This approach is usually related to simple auctions (see [35]), as prices are obtained by intersecting selling and buying quantity-price aggregated bid curves.

Joint markets are characterized by a simultaneous co-optimization of both energy and multiple reserve commodities. GenCos submit and coordinate their bids at a time into the market, existing different cleared prices for each commodity (see [36]). Optimal bids must therefore contemplate the existing interactions between every market. Although this approach might be used in simple auctions (where energy and reserve markets should be cleared at the same time), it is in complex auctions (see [35]) where joint optimization is widely used. In this type of auction, an optimization algorithm decides the system optimal dispatch according not only to the different bids of each enterprise but also to a set of declared technical characteristics and costs that must accompany each bid.

An alternative dispatching method would be to offer both energy and reserves quantities into the same bid, leading to a unique clearing price, since both commodities are strongly linked. No references related to this mechanism have been found throughout the literature, probably due to the complexity that it entails. Only [21] proposes a model in which reserves are cleared according to the energy bid curve, being paid based on energy's opportunity cost. Hence, a unique auction is proposed and a unique bid curve is needed.

Since joint optimization seems to be more efficient (see [20,37-40]) some real markets such as PJM, ISONE, NYISO, CAISO or ERCOT have gradually evolved from sequential to joint mechanisms. Table II classifies several relevant energy and reserve markets according to their dispatching method.

Table 2: Dispatch methods for market operators

\begin{tabular}{|l|l|}
\hline Sequential Dispatch & OMEL (Spain), GME (Italy), Nord Pool (Nordic countries) \\
\hline Joint dispatch & AEMO (Australia), PJM (EEUU), NYISO (EEUU), New England (EEUU), MISO (EEUU), \\
& CAISO (EEUU), ERCOT (EEUU), \\
\hline
\end{tabular}

\section{General issues on energy and reserve markets modeling}

This section presents the main structural issues to be considered in an energy and reserve model. It should be noted that some of these characteristics can be simplified depending on the scope and objectives of the model (e.g. day-ahead market, real-time market, investment decisions...). They have been divided into two categories: number and nature of reserves modeled, and technical constraints.

\subsection{Modeling reserves}

Due to its common usage in the literature, this section is based on the U.S.A. notation described in section 2, by which reserves are classified into: regulation, spinning/non-spinning reserves and replacement reserves.

\subsubsection{Type of reserves}

For simplicity, the majority of works deal with a unique reserve product. Some authors do not explicit the type of reserve considered (see [41-49]), whereas others refer to spinning reserve (see [14,37-39,50-63]). 
Moreover, the majority of authors take into account only up reserve whereas others integrate both up and down spinning reserves (see $[34,64]$ ). Although these are frequently modeled as independent commodities in the literature, (see $[34,64]$ ), in some markets, up and down reserves are proportionally related (PJM, NYISO, MISO, ISO-NE, Spain) and consequently, a unique decision variable is needed.

A further formulation is to additionally consider non-spinning reserves [65-68] by which units are capable of providing slower reserves, even if they are not already coupled to the grid. Since spinning reserve is graded as a higher quality service, it could also be offered as non-spinning reserve (see [21]).

More complex models extend the unique reserve product to a multi commodity situation. In [69], not only spinning/non spinning reserves but also instantaneous reserves (regulation) are considered.

Finally, the most complete approaches $([36,40,70-73])$ face the whole energy and reserves markets (regulation/, spinning \& non spinning reserves, thirty-minute operational reserve). As in the previous cases, additional constraints, variables and parameters are needed. By this approach, the complexity and the size of the model augment considerably.

\subsubsection{Reserve requirements}

In real markets, reserve requirements are usually determined by the SO and calculated by means of different methods: they can be related to the capacity of the largest unit coupled to the grid, but they can also be based on historical data or take into account the amount of intermittent production or the level of contingencies previewed (see [22-26,28]).

Although these heuristic rules could be directly inputted to models, alternative methods are sometimes proposed, searching better ways to schedule reserves. Some authors $([41,43,45,62,64,67])$ incorporate an "elastic reserve demand" by which the reserve necessities can vary depending on the reserve price. Other approaches compute reserve requirements in a probabilistic way, considering the social welfare and the reliability of the system (see $[40,50,51,55,65,66,68]$ ). In these cases, the expected costs of non-served energy are added to the objective function and are directly connected to reserves necessities.

\subsubsection{Reserve bid curves}

From an economical point of view, reserve bids follow, similarly to energy bids, a non-decreasing staircase function. In terms of modeling, these functions require the usage of binary variables, as in $[38,56,57,66,74]$. Simpler approximations define them as constants (see $[36,37,39,52-54,64,67,70,71]$ ), linear (see $[40,42,43,45,47,48,51,59-62,65,68,69])$ or quadratic functions (see $[14,63,72,73]$ ), which make large-scale problems more manageable. Finally, demand-side reserves supply has been also considered in $[41,42,50-52,64,67,70]$.

\subsubsection{Interaction between commodities (opportunity cost)}

In [49,62], an additional cost is incurred in the objective function so as to explicitly contemplate the energy opportunity cost of providing reserves. In sequential dispatches, the absence of this cost would lead to neglect the interaction between markets, whereas in joint dispatches, this opportunity cost is implicitly taken into account and does not require a term in the objective function.

\subsubsection{Reserve energy used for regulatory purposes}

Offering reserves does not necessarily imply the supply of the capacity cleared, as contingencies and load fluctuations might take place or not. Whereas the payment for reserve capacity is certain, the cost of producing the percentage of energy needed from that called capacity is uncertain. The majority of researchers suppose that the reserves called will have to be wholly supplied as energy (see $[14,34,37,38,40,41,43,47,48,50-57,59-69,72,73])$, while in other approaches, only a percentage of the cleared reserves is assumed $[39,42]$. In probabilistic models, as in $[50,51,55,65,66,68]$ contingencies and load fluctuations are modeled, and so does the real requirements of the capacity asked. An interesting via for addressing this uncertainty could be simulation. 
P. González, J. Villar, C.A. Díaz, F.A. Campos. Joint energy and reserve markets: current implementations and modeling trends. Electric Power Systems Research. vol. 109, pp. 101-111, April 2014. JCR 1.749 (2014), 2.688 (2016).

\subsection{Technical constraints}

Apart from the balance equations (satisfaction of the energy demand and the reserve requirements) and the maximum capacities of the generation units, there are other constraints related namely with transmission networks, unit commitment, inter temporality and hydro-thermal coordination that could be considered in order to output realistic prices and dispatches. However, depending on the goal and the scope of the model, some of these might be simplified.

\subsubsection{Transmission network}

For single-node markets, the system is typically assumed as a single-bus (see $[34,37,42,44,46,49,51,53,55,62,66,67,70,71,73,74])$ in which transmission losses are neglected. In nodal systems, a first approach is to simplify the grid as if they were pipelines, neglecting the electric characteristics of the lines (see $[36,38,48,56])$. For further representations, transmission network constraints are generally simplified using DC models which only determine active power flows, as in [14,39-41,43,45,50,52,59$61,63,64,68,75,76]$. Within these DC models $[75,76]$ consider an estimate of transmission losses. Finally, the most complete models, such as $[47,54,57,65,69,72]$ establish AC models that include both active and reactive power flows, and permit voltage regulation. Although AC models are closer to real systems, they are much more complex to solve, as they include non linear equations. DC models are generally considered more practical than AC models, as they provide satisfactory results with simpler equations and lower computational costs (see [77]).

\subsubsection{Unit commitment}

References [34,37-40,42,50,51,55-57,64,65,67,71,73] forecast the optimal commitment of units (whether they have to be started-up or not). This approach permits an adequate representation of the technical minimum, but it needs the inclusion of binary variables that highly increases the computational time. Other models relax these binary variables in order to tackle large scale systems (see [64]), but it might output unfeasible solutions.

\subsubsection{Temporal constraints}

As the definition of reserves is supported on a temporal basis, it seems essential to take temporal constraints into account in order to obtain realistic schedules of generation units. In addition, some authors (see $[14,42,52,60,61,63])$, have demonstrated the relevance on the market of these inter temporal issues (ramps and responding time for reserves).

Nevertheless, as their inclusion augments the complexity of the mathematical models, many researchers have started with single-period models that do not consider time-scopes, such as [39-41,43,44,47$50,53,56,57,59,62,64,67,69,72,74]$. Within these models, some do constraint the problem by limiting the reserve capacity considering its ramp-rate limit and its responding time (see $[39,50,57,69,72]$ ).

\subsubsection{Hydro-thermal coordination}

As described in [78], hydro-thermal coordination faces diverse problems: stochastic nature of the inflows, topology problems and non-linear production curves. Moreover, the introduction fact that reserves might or might not be used to produce energy complicates the modeling of the stored water in the reservoirs. In addition, hydro-thermal coordination is more related to mid-term planning rather than to short-term planning (reserves are within the short-term scope). Nevertheless, hydro units are highly utilized into reserve markets ([15] shows that $40 \%$ of secondary reserves were provided by hydro units in the Spanish system in 2010), due to their fast-response nature and to their ability to store possible interruptible energy surpluses with pumping units. Hence, in order to obtain realistic results, it seems very necessary to extend the only thermal models to the hydro-thermal energy and reserve coordination models, which would entail the coordination of medium-term with short-term dispatching models.

Within the hydro energy and reserve models found in the literature, [79-82] are price-exogenous and focused on a sole GenCo, [34] centers on building up a feasible dispatch and forgets about prices, $[83,84]$ 

trends. Electric Power Systems Research. vol. 109, pp. 101-111, April 2014. JCR 1.749 (2014), 2.688 (2016).

use lagrangian relaxation that might not necessarily converge, [85] makes strong simplifications on the hydro coordination, [86] deals only with hydro management, [87] presents a very simplified model for thermal units, [88] calculates reserves ex-post, [89,90] do not decide unit commitment decisions (start-up and shutdown) and $[91,92]$ use GA, which generally imply large computational times.

Table III shows a summary of some of the characteristics described in this section. Within the transmission network models, PL refers to "pipelines" and DC and AC to models that take transmission characteristics into account, whereas SN is equivalent to "Single Node". Among reserves, R designates "reserve with no specification", U \& D means up and down, SP and NSP refer to spinning and non spinning reserves, $R G$ is similar to regulation and RR specifies replacement reserve.

Table 3: Classification of energy and reserve models with respect to its principle features

\begin{tabular}{|c|c|c|c|c|c|c|c|c|c|c|c|c|c|c|c|c|c|}
\hline \multirow{3}{*}{\multicolumn{2}{|c|}{$\begin{array}{l}\text { Dispatching method } \\
\text { Thermal ramps } \\
\text { Transmission } \\
\text { network }\end{array}$}} & \multicolumn{8}{|l|}{ Joint } & \multicolumn{8}{|c|}{ Sequential } \\
\hline & & & \multicolumn{4}{|l|}{ No } & \multicolumn{4}{|l|}{ Yes } & \multicolumn{4}{|l|}{ No } \\
\hline & & $\mathrm{AC}$ & $\mathrm{DC}$ & PL & SN & $\mathrm{AC}$ & $\mathrm{DC}$ & PL & SN & $\mathrm{AC}$ & $\mathrm{DC}$ & PL & $\mathrm{SN}$ & $\mathrm{AC}$ & DC & PL & SN \\
\hline \multirow{7}{*}{ Reserves } & $\mathrm{R}$ & & & [48] & [46] & & $\begin{array}{l}{[41]} \\
{[43]} \\
{[45]}\end{array}$ & & $\begin{array}{l}{[42]} \\
{[44]}\end{array}$ & [47] & & & & & & & \\
\hline & $\mathrm{R}(\mathrm{U} \& \mathrm{D})$ & & & & & & [38] & & & & & & & & & & \\
\hline & SP & $\begin{array}{l}{[57]} \\
{[54]}\end{array}$ & $\begin{array}{l}{[14]} \\
{[39]} \\
{[50]} \\
{[52]} \\
{[60]} \\
{[61]} \\
{[63]} \\
{[75]}\end{array}$ & [38] & $\begin{array}{l}{[51]} \\
{[55]}\end{array}$ & & [59] & [56] & $\begin{array}{l}{[37]} \\
{[74]} \\
{[53]}\end{array}$ & & [39] & [38] & & & & & $\begin{array}{l}{[37]} \\
{[62]}\end{array}$ \\
\hline & $\begin{array}{l}\text { SP } \\
(\mathrm{U} \& \mathrm{D})\end{array}$ & & & & [34] & & & & & & & & & & & & \\
\hline & SP/NSP & {$[65]$} & $\begin{array}{l}{[68]} \\
{[76]}\end{array}$ & & & & & & [67] & & & & [66] & & & & \\
\hline & $\begin{array}{l}\text { RG+ } \\
\text { SP/NSP }\end{array}$ & [69] & & & & & & & & & & & & & & & \\
\hline & $\begin{array}{l}\text { RG+ } \\
\text { SP/NSP+ } \\
\text { RR }\end{array}$ & $\begin{array}{l}{[40]} \\
{[72]}\end{array}$ & & & $\begin{array}{l}70] \\
{[71]} \\
{[73]}\end{array}$ & & & [36] & & [40] & & & [70] & & & & \\
\hline
\end{tabular}

\section{Modeling methods for energy and reserve markets}

\subsection{Joint vs. sequential dispatch}

As noted in section 3, two different dispatching methods are commonly used among markets: joint and sequential dispatch. Many authors $([14,34,36-46,48,50-57,59-61,63,65,67-76])$ opt for a joint optimization modeling, whereas [37-39,47,62,66,70] adopt sequential dispatches As it is exposed in [20,37-40], joint optimization seems to provide more efficient dispatches (from an economic point of view), but is usually proposed to solve complex auctions where bidders must declare their units technical constraints such as ramps or minimum start-up times. On the contrary, sequential optimization is more appropriate for simple quantity-price auctions for both energy and reserves but with less efficient dispatches. 
P. González, J. Villar, C.A. Díaz, F.A. Campos. Joint energy and reserve markets: current implementations and modeling trends. Electric Power Systems Research. vol. 109, pp. 101-111, April 2014. JCR 1.749 (2014), 2.688 (2016).

\subsection{Centralized vs. Oligopolistic dispatch}

Two main approaches can be utilized for modeling the markets, depending on their own nature: centralized dispatch, that minimize the total system costs, and oligopolistic market models, where the different competitive behaviors of each GenCo and their influence into the market are considered. Oligopolistic dispatches are more appropriate for real markets, but as they require a higher degree of mathematical complexity and computational times, centralized dispatches are usually an alternative for more practical or simpler applications.

\subsubsection{Centralized/Perfect competition dispatch}

The centralized dispatch is focused on obtaining market clearances that minimize electric system costs and maintain the reliability of the system. This approach does not include strategic behaviors of GenCos in the spot market auctions, and therefore, no market power can be modeled.

Differences between the diverse models are given by the structural aspects introduced in section 4: the way to model reserves, the constraints taken into account and the dispatch and solution methodology. Table III includes the centralized dispatches found, which correspond to references $[34,36-38,40-42,50-57,64-$ $73,93]$.

In centralized dispatches, optimization methods are applied due to its rapidness and effectiveness. Linear and Quadratic programming (LP and QP) are used whenever is possible in [36,41,52,68,70] (absence or relaxation of binary variables), whereas Mixed-Integer programming (MIP) is commonly used for unit commitments (see $[34,42,50,51,53,55,64,67]$ ). Non-linear programming (NLP) has been implemented in $[57,65,72]$ whenever non linearities arise (e.g. AC models). This technique is more complex and more timeconsuming. Heuristic methods have been also used, such as genetic algorithms or differential evolution $[56,66]$. Their capability to tackle any type of constraint and the output of diverse candidates to the best objective value are their most interesting advantages, although they do not guarantee the optimal solution and tend to be slower.

\subsubsection{Oligopolistic dispatch}

The problem of modeling electricity markets has been thoroughly studied during the last decade. References [12,13] have made extensive reviews on these modeling trends. For the oligopolistic case, Game theory approaches seem the most appropriate, although other approaches might be contemplated.

\subsubsection{Game theory}

The development of models based on game-theory, mainly Nash-equilibrium, has been proved to be very suitable for the medium and the long term analysis, as they permit the computation of the strategic behavior for every GenCo. Whereas there is a vast amount of work done on energy markets (see [12,13]), only a few works formulate multi commodity equilibria. Moreover, these models generally use non-chronological demand representations as a simplification (see [46]). Hence, inter-temporal constraints are not considered, and reserve issues, related to temporal issues, are not properly modeled.

Finally, existence and uniqueness of the joint equilibrium has been discussed in [46,94,95], but only under specific circumstances. Nevertheless, joint energy and reserve equilibria solutions are not generally unique, and their existence is not always guaranteed.

Mathematical Problems with Equilibrium Constraints (MPECs) and Equilibrium Problems with Equilibrium Constraints (EPECs) are developed in [14,47,48,59-61,63]. As their corresponding KarushKhun-Tucker equations (KKT) are difficult to be solved, [46] proposes the formulation of an equivalent optimization problem, which is solvable only under determined hypothesis. Finally, Lagrangian Relaxation has been used in $[37,71,73]$ in order to tackle the existing complexities of the problem, although they do not guarantee an optimal solution.

In this paper, game theory models have been classified according to $[3,12,96]$ (see figure 3 ). 

trends. Electric Power Systems Research. vol. 109, pp. 101-111, April 2014. JCR 1.749 (2014), 2.688 (2016).

Cournot equilibrium is used in [43-45,74], but none of these references consider temporal constraints, assuming a single-period market. This hypothesis is also assumed in the Stackelberg formulation made in [48].

The extension of the Supply Function Equilibrium (SFE) from an only energy market to an energy and reserve market is not trivial, and requires the resolution of a set of differential equations (although iterative algorithms have been also proposed, [97]). The existence of multiple equilibria might even be more probable than in the only energy case, as the space of possible solutions for a competitor gains in dimensions $(R$ reserve commodities +1 for energy). Probably due to these complexities, only three SFE models $([14,39,47,63])$ considering both energy and reserves have been found in the literature.

Joint energy and reserve Conjectural Equilibrium (CE) and Conjectural Supply Function Equilibrium (CSFE) models are also scarce, probably due to similar drawbacks. First of all, as in the SFE case, the system of equations resulting from the formulation of the combined energy and reserve equilibrium is complicated. Reference [46] proves that the interaction between commodities leads to the appearance of four different conjectures, augmenting the dimension of the problem and the difficulty in their calculus. Moreover, reference [98] demonstrates that the addition of constraints in the energy only case have important effects on conjectures (it must be noted that the inclusion of reserves add new extra constraints as pointed out in section 4). Finally, the existence and uniqueness of the energy and reserve equilibrium have been only discussed for determined situations (see [46,94,95]).

Despite the difficulties mentioned above, some exogenous approaches have been developed in [59-62], where conjectures have been calculated ex-ante, resulting into fixed parameters for the resolution of the problem.

\subsubsection{Other approaches}

Apart from game-theory models, oligopolistic behavior in the energy and reserve markets can be also obtained by means of other techniques, such as models based on a sole enterprise, in which price is an exogenous variable. References [79-82] are some examples of this modeling trends.

It should be noted that as authors are focused on equilibrium models, a further revision of the literature should be done on these other alternatives.

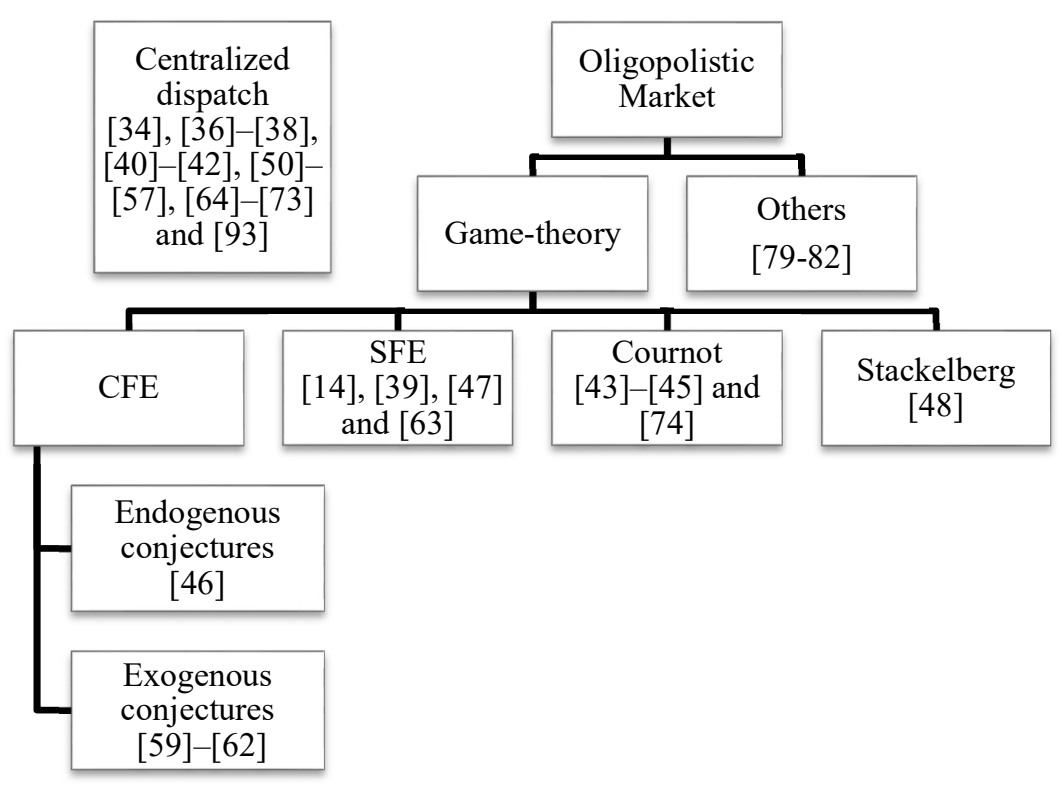

Figure 3: Structural classification of the energy and reserve models. 


\section{Theoretical oligopolistic equilibrium model}

This section proposes a general mathematical formulation for an energy and reserve (up and down reserves related by a certain factor) equilibrium model that integrates the most relevant issues that, as discussed in the previous sections, should be contemplated. Note that, if a relation between up and down reserves is assumed, a unique market is held for both reserves, as it is the case of Spain or Portugal. Furthermore, the formulation exposed below could be extended to a multi-commodity dispatch (multiple reserves) by applying additional variables, constraints and hierarchical relations, as in [72]. As a first approximation, no technical constraints apart from the balance equation and the maximum capacity of each generation unit will be considered. The system will be assumed as a single-node with no transmission losses in which a multi-period market with inelastic demand is held. This approach is based on the only energy equilibrium explicated in [96]. Both joint and sequential dispatch formulations are exposed. Finally, the main additional technical constraints that should be considered in order to develop a realistic model are enumerated.

\subsection{Joint dispatch}

Let us consider a system constituted by one energy market and one combined up and down reserve commodities market, in which $N$ GenCos submit bids for both markets. For each period $h$, let us assume a certain energy demand $D_{h}^{E}$ and a certain level of reserve requirements $D_{h}^{U R}$ and $D_{h}^{D R}$. If each GenCo $i$ clears $q_{i, h}^{E} \mathrm{MWh}$ of energy and $q_{i, h}^{U R}$ and $q_{i, h}^{D R} \mathrm{MW}$ of reserve, the balance equations are:

$$
D_{h}^{E}=\sum_{i} q_{i, h}^{E} ; \quad D_{h}^{U R}+D_{h}^{D R}=\sum_{i}\left(q_{i, h}^{U R}+q_{i, h}^{D R}\right) \quad \forall h
$$

Note that up and down reserves must be related for each GenCo by a factor $\rho_{h}$ :

$$
q_{i, h}^{D R}=q_{i, h}^{U R} \cdot \rho_{h} \quad \forall h
$$

If the maximum capacity of each GenCo is $Q_{i}^{\max }$, the capacity constraint leads to:

$$
q_{i, h}^{E}+q_{i, h}^{U R} \leq Q_{i}^{\max } \quad \forall i, h
$$

Furthermore, down reserve cannot be higher than energy:

$$
q_{i, h}^{D R} \leq q_{i, h}^{E} \quad \forall i, h
$$

If the energy and reserve spot prices are denoted as $\lambda_{h}^{E}, \lambda_{h}^{R}$, the benefits of each GenCo $i$ will be equal to:

$$
\begin{aligned}
& B_{i}\left(q_{i, h}^{E}, q_{-i, h}^{E}, q_{i, h}^{U R}, q_{-i, h}^{U R}\right)= \\
& \quad \sum_{h}\left\{\begin{array}{l}
\lambda_{h}^{E}\left(q_{i, h}^{E}, q_{-i, h}^{E}, q_{i, h}^{U R}, q_{-i, h}^{U R}\right) \cdot q_{i, h}^{E} \\
+\lambda_{h}^{R}\left(q_{i, h}^{E}, q_{-i, h}^{E}, q_{i, h}^{U R}, q_{-i, h}^{U R}\right) \cdot q_{i, h}^{U R} \cdot\left(1+\rho_{h}\right) \\
+\lambda_{h}^{E}\left(q_{i, h}^{E}, q_{-i, h}^{E}, q_{i, h}^{U R}, q_{-i, h}^{U R}\right) \cdot q_{i, h}^{U R} \cdot\left(\alpha_{i, h}^{U R}-\rho_{h} \cdot \alpha_{i, h}^{D R}\right) \\
-C_{i}\left(q_{i, h}^{E}+q_{i, h}^{U R} \cdot\left(\alpha_{i, h}^{U R}-\rho_{h} \cdot \alpha_{i, h}^{D R}\right)\right)
\end{array}\right\}
\end{aligned}
$$

where:

$$
q_{-i, h}^{E}=\sum_{j \neq i} q_{j, h}^{E} ; q_{-i, h}^{U R}=\sum_{j \neq i} q_{j, h}^{U R}
$$

The first two terms of the benefit function correspond to the incomes from the energy and the reserve markets. As showed in the formulation, both prices depend on all the decision variables of the problem (every GenCo's energy and reserve quantities). Note that since $q_{i, h}^{D R}$ is strictly related to $q_{i, h}^{U R}$ by equation (2), only 
one decision variable is needed. Percentages $\alpha_{i, h}^{U R}$ and $\alpha_{i, h}^{D R}$ of up and down reserve are supposed to be provided as regulating energy. Thus, the third income/cost of the benefit function reflects its payment at the energy price. Finally, the GenCo has a variable cost for producing energy and energy devoted to regulatory purposes. For simplicity, start up and shut down costs have not been contemplated.

Under these assumptions, each GenCo maximizes its profits (5) with respect to its decision variables, and using (2), the following Nash equilibrium equations are obtained:

$$
\begin{aligned}
& \frac{\partial B_{i}}{\partial q_{i, h}^{E}}=0 \quad \forall i, h \\
& \Rightarrow \frac{\partial \lambda_{h}^{E}}{\partial q_{i, h}^{E}} \cdot\left(q_{i, h}^{E}+q_{i, h}^{U R} \cdot\left(\alpha_{i, h}^{U R}-\rho_{h} \cdot \alpha_{i, h}^{D R}\right)\right)+\lambda_{h}^{E}+\frac{\partial \lambda_{h}^{R}}{\partial q_{i, h}^{E}} \cdot q_{i, h}^{U R} \cdot\left(1+\rho_{h}\right)=\frac{\partial C_{i}\left(q_{i, h}^{E}+q_{i, h}^{U R} \cdot\left(\alpha_{i, h}^{U R}-\rho_{h} \cdot \alpha_{i, h}^{D R}\right)\right)}{\partial q_{i, h}^{E}} \\
& \frac{\partial B_{i}}{\partial q_{i, h}^{U R}}=0 \quad \forall i, h \\
& \Rightarrow \frac{\partial \lambda_{h}^{E}}{\partial q_{i, h}^{U N}} \cdot\left(q_{i, h}^{E}+q_{i, h}^{U R} \cdot\left(\alpha_{i, h}^{U R}-\rho_{h} \cdot \alpha_{i, h}^{D R}\right)\right)+\frac{\partial \lambda_{h}^{R}}{\partial q_{i, h}^{U R}} \cdot q_{i, h}^{U R} \cdot\left(1+\rho_{h}\right)+\lambda_{h}^{R} \cdot\left(1+\rho_{h}\right)+\lambda_{h}^{E} \cdot\left(\alpha_{i, h}^{U R}-\rho_{h} \cdot \alpha_{i, h}^{D R}\right)=\frac{\partial C_{i}\left(q_{i, h}^{E}+q_{i, h}^{U R} \cdot\left(\alpha_{i, h}^{U R}-\rho_{h} \cdot \alpha_{i, h}^{D R}\right)\right)}{\partial q_{i, h}^{U R}}
\end{aligned}
$$

In order to model the strategic behavior of GenCos, instead of a unique type of conjecture, as in the only energy approach, four conjectures are obtained for each GenCo in the equilibrium: $\partial \lambda_{h}^{E} / \partial q_{i, h}^{E}, \partial \lambda_{h}^{E} / \partial q_{i, h}^{U R}$ $\partial \lambda_{h}^{R} / \partial q_{i, h}^{E}$ and $\partial \lambda_{h}^{R} / \partial q_{i, h}^{U R}$ as can be seen in equations (7) and (8).

In addition, the system of partial derivatives gains in dimensions and its resolution appears to be much more difficult, due to the existence of crossed terms (reserve components in the energy equation and viceversa).

If a multi-reserve dispatch is considered, equations (7) and (8) should be complemented with newer equations for each new decision variable, and the appearance of new conjectures would entail higher complexities. In addition, in a sequential approach, the number of steps would increase.

The authors are currently studying this problem, and, as a first approach, two different possibilities are proposed: on the one hand, the elaboration of the complementary problem by using the Karush-Kuhn-Tucker equations and, on the other hand, the elaboration of an equivalent optimization problem. The first approach permits the usage of non linear equations, but its application to large scale systems is harder to implement and the consideration of constraints is limited in order to avoid high computational times. The second approach deals with high dimension problems with no difficulties and permits the inclusion of constraints, but it requires the formulation of an equivalent integral function to the system of equilibrium equations (see [46]), which existence, for the combined energy and reserve case, has not even been demonstrated yet.

\subsection{Sequential dispatch}

In the sequential dispatch approach, the energy market is cleared first. This step has already been discussed in [99] and hence, only the reserve market will be addressed hereafter. It will be assumed that the energy prices $\lambda_{h}^{E^{*}}$ have already been determined, and so do the optimal energy supplies $q_{i, h}^{E^{*}}$ of each GenCo. Nevertheless, the GenCos can reprogram their units in order to offer reserve, leading to a variation $\Delta q_{i, h}^{E}$ in their energy program. In this case, the opportunity cost of producing regulating energy must be considered, leading to the next benefit function: 


$$
\begin{aligned}
& B_{i}\left(\Delta q_{i, h}^{E}, \Delta q_{-i, h}^{E}, q_{i, h}^{U R}, q_{-i, h}^{U R}\right)= \\
& \sum_{h}\left\{\begin{array}{l}
\lambda_{h}^{E^{*}} \cdot \Delta q_{i, h}^{E} \\
+\lambda_{h}^{R}\left(\Delta q_{i, h}^{E}, \Delta q_{-i, h}^{E}, q_{i, h}^{U R}, q_{-i, h}^{U R}\right) \cdot q_{i, h}^{U R} \cdot\left(1+\rho_{h}\right) \\
+\lambda_{h}^{E^{*}} \cdot q_{i, h}^{U R} \cdot\left(\alpha_{i, h}^{U R}-\alpha_{i, h}^{D R} \cdot \rho_{h}\right) \\
\left(\begin{array}{l}
C_{i}\left(q_{i, h}^{E}+\Delta q_{i, h}^{E}+q_{i, h}^{U R} \cdot\left(\alpha_{i, h}^{U R}-\alpha_{i, h}^{D R} \cdot \rho_{h}\right)\right) \\
-C_{i}\left(q_{i, h}^{E}\right)
\end{array}\right)
\end{array}\right\}
\end{aligned}
$$

The first terms correspond to the income/cost due to the deviation from the original energy program. The following terms show the benefits for both the reserve band and the regulating energy used. This problem is very similar to the joint dispatch problem that has been already presented. However, the authors are currently working on a simplification of $\Delta q_{i, h}^{E}$ as a function of $q_{i, h}^{U R}$, which would lead to a unique decision variable per GenCo, and could be solved in a similar way to the previous only energy auction.

\subsection{Technical constraints}

The following constraints are formulated for the joint dispatch. Nevertheless, as the sequential dispatch can be interpreted as a specific case of the joint dispatch, these constraints could also be applied to the sequential case under the same hypothesis of subsection 6.2 (energy market cleared first and subsequent dispatch of reserves with $\lambda_{h}^{E^{*}}$ and $q_{i, h}^{E^{*}}$ fixed and $\Delta q_{i, h}^{E}$ permitted).

Let us suppose that each GenCo owns a set of generation units. Hence, all previous variables (energy and up and down reserves) must be particularized for each unit $g$ as $q_{g, i, h}^{E}, q_{g, i, h}^{U R}$ and $q_{g, i, h}^{D R}$. Furthermore, a single node system will be assumed, which will be structured in hourly periods, in order to capture a realistic effect of ramps $Q_{g, i}^{R M P D}$ and $Q_{g, i}^{R M P U}$ and reserves time response $t^{D R}$ and $t^{U R}$. Moreover let us suppose that the unit commitment has already been fixed and that parameters $U_{g, t, h}$ refer to the hourly state of each unit (whether or not connected to the system). For simplicity hydro-thermal coordination equations have not been included, but they should also be taken into account.

Under these assumptions, for every GenCo $i$, the benefit function becomes:

$$
\begin{aligned}
& B_{i}\left(q_{i, h}^{E}, q_{-i, h}^{E}, q_{i, h}^{U R}, q_{-i, h}^{U R},\right)= \\
& \sum_{h}\left\{\begin{array}{l}
\lambda_{h}^{E}\left(q_{i, h}^{E}, q_{-i, h}^{E}, q_{i, h}^{U R}, q_{-i, h}^{U R}\right) \cdot q_{i, h}^{E} \\
+\lambda_{h}^{R}\left(q_{i, h}^{E}, q_{-i, h}^{E}, q_{i, h}^{U R}, q_{-i, h}^{U R}\right) \cdot q_{i, h}^{U R} \cdot\left(1+\rho_{h}\right) \\
+\lambda_{h}^{E}\left(q_{i, h}^{E}, q_{-i, h}^{E}, q_{i, h}^{U R}, q_{-i, h}^{U R}\right) \cdot q_{i, h}^{U R} \cdot\left(\alpha_{i, h}^{U R}-\rho_{h} \cdot \alpha_{i, h}^{D R}\right)
\end{array}\right\} \\
& \quad-\sum_{g, h} C_{g, i}\left(q_{g, i, h}^{E}+q_{g, i, h}^{U R} \cdot\left(\alpha_{i, h}^{U R}-\rho_{h} \cdot \alpha_{i, h}^{D R}\right)\right)
\end{aligned}
$$

where:

$$
q_{i, h}^{E}=\sum_{g} q_{g, i, h}^{E} \text { and } q_{i, h}^{U R}=\sum_{g} q_{g, i, h}^{U R}
$$

In addition, the next constraints should be considered.

Capacity constraints (where $Q_{g, i}^{\max }$ and $Q_{g, i}^{\min }$ represent the maximum capacity and the technical minimum): 


$$
\left.\begin{array}{l}
q_{g, i, h}^{E}+q_{g, i, h}^{U R} \leq Q_{g, i}^{\max } \cdot U_{g, i, h} \\
q_{g, i, h}^{E}-q_{g, i, h}^{D R} \geq Q_{g, i}^{\min } \cdot U_{g, i, h}
\end{array}\right\} \quad \forall g, i, h
$$

Up and down reserves relation:

$$
\sum_{g} q_{g, i, h}^{U R}=\rho_{h} \cdot \sum_{g} q_{g, i, h}^{D R} \quad \forall i, h
$$

\section{$\underline{\text { Ramping constraints: }}$}

$$
\left.\begin{array}{l}
\left(q_{g, i, h+1}^{E}+q_{g, i, h+1}^{U R}\right)-\left(q_{g, i, h}^{E}-q_{g, i, h}^{D R}\right) \leq Q_{g, i}^{R M P U} \cdot U_{g, i, h+1} \\
\left(\begin{array}{c}
E \\
q_{g, i, h}+q_{g, i, h}^{U R}
\end{array}\right)-\left(q_{g, i, h+1}^{E}-q_{g, i, h+1}^{D R}\right) \leq Q_{g, i}^{R M P D} \cdot U_{g, i, h}
\end{array}\right\} \forall g, i, h
$$

\section{Reserve time responses:}

$$
\left.\begin{array}{l}
q_{g, i, h}^{U R} \leq Q_{g, i}^{R M P U} \cdot t^{U R} \cdot U_{g, i, h} \\
q_{g, i, h}^{D R} \leq Q_{g, i}^{R M P D} \cdot t^{D R} \cdot U_{g, i, h}
\end{array}\right\} \quad \forall g, i, h
$$

\section{Conclusions}

This paper presents an extensive literature review on energy and reserves market implementations and modeling, provides some insights on the existing difficulties that arise in the formulation and implementation of this approach, and proposes a general simplified formulation for a single node system.

A first revision on real systems has revealed that the problem can be tackled in very different ways, depending on the market system characteristic (nodal or single-bus), the dispatching method (sequential vs. joint) or the ancillary services considered (typically frequency and load regulation divided into primary, secondary and tertiary reserves). In addition to these factors, new possible market designs might arise, as, for instance, the existence of a unique market in which the whole group of services is cleared by means of a unique offer.

It has been pointed out that reserve modeling requires the consideration of short-term constraints such as the ramping limits of the generation units or the responding times of reserves. In addition, reserves are related to uncertain contingencies, reinforcing the stochastic/probabilistic dimension of the problem. It also requires the formulation of interaction factors between commodities as, for instance, lost opportunity costs between services, or the dependency of reserve requirements on energy demand.

Centralized dispatches have been thoroughly studied and a wide variety of models have been elaborated leading to interesting results. A challenging via for future work will be the study of the coupling between medium-term decisions (hydrothermal coordination, fuel and maintenance planning, etc.) with these shortterm centralized energy and reserve market models.

On the contrary, oligopolistic models, have not yet reached the same level of maturity for the combined energy and reserve dispatch than for the only energy dispatch. As shown in this paper, the degree of mathematical complexity turns out to be considerably higher. Furthermore, the inclusion of additional variables and constraints critically increases the size of the problem, and consequently, the expected computational times. These drawbacks will surely be some of the challenges that future works will have to cope with.

\section{References}

[1] J.T. Saraiva, H. Heitor, N. Correia, R. Araújo, Ancillary services-The current situation in the iberian electricity market and future possible developments, in: PowerTech, 2011 IEEE Trondheim, 2011: pp. 1-8. 
P. González, J. Villar, C.A. Díaz, F.A. Campos. Joint energy and reserve markets: current implementations and modeling trends. Electric Power Systems Research. vol. 109, pp. 101-111, April 2014. JCR 1.749 (2014), 2.688 (2016).

[2] P.D. Klemperer, M.A. Meyer, Supply Function Equilibria in Oligopoly under Uncertainty, Econometrica. 57 (1989) $1243-$ 77.

[3] C.J. Day, B.F. Hobbs, Jong-Shi Pang, Oligopolistic competition in power networks: a conjectured supply function approach, IEEE Transactions on Power Systems. 17 (2002) 597- 607.

[4] R. Baldick, R. Grant, E. Kahn, Theory and application of linear supply function equilibrium in electricity markets, Journal of regulatory economics. (2004) 143-167.

[5] A. Motamedi, M. Fotuhi-Firuzabad, Ancillary Service Markets, in: 2007 Large Engineering Systems Conference on Power Engineering, IEEE, 2007: pp. 316-320.

[6] E. Lobato Miguélez, I. Egido Cortés, L. Rouco Rodríguez, G. López Camino, An overview of ancillary services in Spain, Electric Power Systems Research. 78 (2008) 515-523.

[7] R. Raineri, S. Ríos, D. Schiele, Technical and economic aspects of ancillary services markets in the electric power industry: an international comparison, Energy Policy. 34 (2006) 1540-1555.

[8] Gumersindo Queijo, Integrating renewable energy into the Spanish energy networks - Technology challenges, 15-Sep2010. [Online]. Available http://www.google.es/url? sa=t\&rct=j\&q=\&esrc=s\&source=web\&cd $=1 \&$ cad $=$ rja \&ved $=0 \mathrm{CDMQ}$ FjAA\&url=http $\% 3 \mathrm{~A} \% 2 \mathrm{~F} \% 2 \mathrm{Fwww}$.erranet.org\%2Findex.php\%3Fname\%3DOE-Library $\% 26$ file $\% 3$ Ddownload $\% 26 \mathrm{id} \%$ 3D7174\%26keret\%3DN\%26showheader\%3DN\&ei=4ItnUsatK4OthQes5YHYCA\&usg=AFQjCNF47RN4Cidapa8QAmE ehbTignJ_ig\&bvm=bv.55123115,d.ZG4; [Accessed: 23-Oct-2013].

[9] C.J. Artaiz, M.I. Docavo, N. Martins, M. Rosa, M.N. Tavares, R. Ferreira, et al., Evaluación de los niveles adecuados de reserva de operación en los sistemas eléctricos ibéricos a medio y largo plazo, XIII Encuentro Regional Iberoamericano de Cigré, Argentina. (2009) 24-28.

[10] E. Ela, B. Kirby, E. Lannoye, M. Milligan, D. Flynn, B. Zavadil, et al., Evolution of operating reserve determination in wind power integration studies, in: 2010 IEEE Power and Energy Society General Meeting, 2010: pp. 1-8.

[11] E. Ela, M. Milligan, B. Kirby, Operating Reserves and Variable Generation, Technical Report, NREL (National Renewable Energy Laboratory), NREL/TP-5500-51978, 2011.

[12] M. Ventosa, Á. Baíllo, A. Ramos, M. Rivier, Electricity market modeling trends, Energy Policy. 33 (2005) 897-913.

[13] G. Li, Modeling methods for GenCo bidding strategy optimization in the liberalized electricity spot market-A state-of-theart review, Energy. 36 (2011) 4686-4700.

[14] H. Haghighat, H. Seifi, A.R. Kian, Gaming Analysis in Joint Energy and Spinning Reserve Markets, IEEE Transactions on Power Systems. 22 (2007) 2074-2085.

[15] REE (Red eléctrica de España). [Online]. Available http://www.ree.es/; [Accessed: 25-May-2012].

[16] Ministerio de industria, turismo y comercio de España, Plan de acción nacional de energías renovables en España (PANER) 2011-2020, 30-Jun-2010. [Online]. Available http://www.minetur.gob.es/energia/desarrollo/EnergiaRenovable/ Documents/20100630_PANER_Espanaversion_final.pdf; [Accessed: 24-May-2012].

[17] Federal energy regulatory comission (FERC) of the United States of America, Order No. 888, 24-Apr-1996. [Online]. Available http://www.ferc.gov/legal/maj-ord-reg/land-docs/order888.asp; [Accessed: 24-May-2012].

[18] A. Carbajo Josa, Los mercados eléctricos y los servicios de ajuste del sistema, Economía industrial. (2007) 55-62.

[19] Kirby B, Frequency Regulation Basics and Trends, Oak Ridge National Laboratory Report, ORNL/TM-2004/291, 2004.

[20] Kirby, Ancillary Services: Technical and Commercial Insights, Prepared for Wartsila. 39 (2007) 1-4, v.

[21] S.S. Oren, R. Sioshansi, Joint Energy and Reserves Auction with Opportunity Cost Payment for Reserves, UCEI, EPE 008. University of California Energy Institute (2003).

[22] CAISO, Settlements Guide: Charge \#111 Spinning reserve due ISO and Charge \#112 Non-spinning reserve due ISO, 312006. [Online]. Available http://www.caiso.com/docs/2003/09/08/2003090815135425649.pdf; [Accessed: 26-May-2012].

[23] NERC, Ancillary services matrix. [Online]. Available http://www.nerc.com/docs/pc/ivgtf/NERC_ancillary_services $\% 20$ ERCOT\%20IESO $\% 20 \mathrm{NYISO} \% 20 \mathrm{MISO} \% 20 \mathrm{PJM} \% 20$ SPP\%20WECC\%2012\%2014.pdf; [Accessed: 26-May-2012].

[24] PJM State \& Member Training Department, Reserves scheduling, reporting and loading, Operations 101, 10-Sep-2012. [Online]. Available http://www.pjm.com/ /media/training/core-curriculum/ip-ops-101/ops-101-reserves.ashx; [Accessed: 26-May-2012].

[25] New York independent system operator, Ancillary services manual, Oct-2011. [Online]. Available http://www.nyiso.com/public/webdocs/documents/manuals/operations/ancserv.pdf; [Accessed: 26-Feb-2013].

[26] ISO New England, Operating Procedure No. 8 Operating Reserve and Regulation, Jan-2011. [Online]. Available http://www.iso-ne.com/rules_proceds/operating/isone/op8/op8_rto_final.pdf; [Accessed: 26-May-2012].

[27] ERCOT - Operating Procedures. [Online]. Available http://www.ercot.com/mktrules/guides/procedures/; [Accessed: 08Jan-2013].

[28] Mid west system operator, MISO Integration Training- Energy and operating reserve markets, 05-Mar-2012. [Online]. Available https:/www.midwestiso.org/Library/Repository/Meeting\%20Material/Stakeholder/Training\%20Materials/ 200\%20Level\%20Training/Level\%20200\%20-\%20Energy\%20and\%20Operating\%20Reserves\%20Markets.pdf; [Accessed: 21-Feb-2013]. 
P. González, J. Villar, C.A. Díaz, F.A. Campos. Joint energy and reserve markets: current implementations and modeling

trends. Electric Power Systems Research. vol. 109, pp. 101-111, April 2014. JCR 1.749 (2014), 2.688 (2016).

[29] E. Rivero, J. Barquin, L. Rouco, European balancing markets, in: Energy Market (EEM), 2011 8th International Conference on the European, IEEE, 2011: pp. 333-338.

[30] Ministerio de industria, turismo y comercio de España, BOE 8813, 18-May-2009. [Online]. Available http://www.boe.es/boe/dias/2012/07/02/pdfs/BOE-A-2012-8813.pdf; [Accessed: 24-May-2012].

[31] Pablo Ledesma, Regulación de frecuencia y potencia, 21-Sep-2008. [Online]. Available http://ocw.uc3m.es/ingenieriaelectrica/operacion-y-control-de-sistemas-electricos/regulacion-de-frecuencia-potencia; [Accessed: 21-Feb-2013].

[32] E. Saiz-Marin, J. Garcia-Gonzalez, J. Barquin, E. Lobato, Economic Assessment of the Participation of Wind Generation in the Secondary Regulation Market, IEEE Transactions on Power Systems. 27 (2012) 866-874.

[33] J. Villar, A. Munoz, E.F. Sanchez-Ubeda, A. Mateo, M. Casado, A. Campos, et al., SGO: management information system for strategic bidding in electrical markets, in: Power Tech Proceedings, 2001 IEEE Porto, 2001: p. 6.

[34] J. Garcia-Gonzalez, A.M. San Roque, F.A. Campos, J. Villar, Connecting the Intraday Energy and Reserve Markets by an Optimal Redispatch, IEEE Transactions on Power Systems. 22 (2007) 2220-2231.

[35] T. Gómez, Electricity distribution. Chapter 5, in: The Regulation of the Power Sector to be published by Springer, Springer New York, 2011.

[36] X. Ma, D. Sun, K. Cheung, Energy and reserve dispatch in a multi-zone electricity market, IEEE Transactions on Power Systems. 14 (1999) 913-919.

[37] Y. Chen, P.B. Luh, J.H. Yan, G.A. Stern, W.E. Blankson, Payment cost minimization for simultaneous auctions in energy and spinning reserve markets, in: Power Engineering Society General Meeting, 2006. IEEE, 2006: p. 8-pp.

[38] Z. Ming, L. Gengyin, L. Huijuan, L. Guanqi, Research on daily trading plan considering spinning reserve in power market, in: TENCON'02. Proceedings. 2002 IEEE Region 10 Conference on Computers, Communications, Control and Power Engineering, 2002: pp. 1805-1808.

[39] S. Soleymani, A.M. Ranjbar, A.R. Shirani, New approach for strategic bidding of Gencos in energy and spinning reserve markets, Energy Conversion and Management. 48 (2007) 2044-2052.

[40] F.D. Galiana, F. Bouffard, J.M. Arroyo, J.F. Restrepo, Scheduling and Pricing of Coupled Energy and Primary, Secondary, and Tertiary Reserves, Proceedings of the IEEE. 93 (2005) 1970-1983.

[41] M. Aganagic, K. Abdul-Rahman, J. Waight, Spot pricing of capacities for generation and transmission of reserve in an extended poolco model, Power Systems, IEEE Transactions on. 13 (1998) 1128-1135.

[42] Yun Tiam Tan, D.S. Kirschen, Co-optimization of Energy and Reserve in Electricity Markets with Demand-side Participation in Reserve Services, in: Power Systems Conference and Exposition, 2006. PSCE '06. 2006 IEEE PES, IEEE, 2006: pp. 1182-1189.

[43] Dawei Huang, Xueshan Han, Xiangxing Meng, Zhizhong Guo, Analysis of Nash Equilibrium Considering Multicommodity Trade in Coupled Constraint Electricity Markets, in: International Conference on Power System Technology, 2006. PowerCon 2006, IEEE, 2006: pp. 1-6.

[44] M.S. Nazir, F.D. Galiana, Cournot Gaming in Joint Energy and Reserve Markets, in: 2011.

[45] D. Chattopadhyay, Multicommodity spatial Cournot model for generator bidding analysis, IEEE Transactions on Power Systems. 19 (2004) 267-275.

[46] J. Villar, F.A. Campos, C.A. Diaz, Short term constraints for a long term joint energy and reserve equilibrium, in: IEEE, 2011: pp. 81-86.

[47] P. Chitkara, Jin Zhong, K. Bhattacharya, Oligopolistic Competition of Gencos in Reactive Power Ancillary Service Provisions, IEEE Transactions on Power Systems. 24 (2009) 1256-1265.

[48] Jinye Zhao, B. Brereton, M. Montalvo, Gaming-Based Reserve Constraint Penalty Factor Analysis, IEEE Transactions on Power Systems. 26 (2011) 616-626.

[49] A.G. Morinec, F.E. Villaseca, Optimal generator bidding strategies for power and ancillary services using game theory, in: Power Symposium, 2008. NAPS '08. 40th North American, IEEE, 2008: pp. 1-8.

[50] A. Ahmadi-Khatir, R. Cherkaoui, A probabilistic joint energy and spinning reserve market model, in: Power and Energy Society General Meeting, 2010 IEEE, 2010: pp. 1-6.

[51] F. Aminifar, M. Fotuhi-Firuzabad, M. Shahidehpour, Unit Commitment With Probabilistic Spinning Reserve and Interruptible Load Considerations, IEEE Transactions on Power Systems. 24 (2009) 388-397.

[52] A.L. Costa, A.S. Costa, Energy and ancillary service dispatch through dynamic optimal power flow, in: Power Tech Conference Proceedings, 2003 IEEE Bologna, IEEE, 2003.

[53] Deqiang Gan, E. Litvinov, Energy and reserve market designs with explicit consideration to lost opportunity costs, IEEE Transactions on Power Systems. 18 (2003) 53- 59.

[54] Jie Chen, J.S. Thorp, R.J. Thomas, T.D. Mount, Locational pricing and scheduling for an integrated energy-reserve market, in: Proceedings of the 36th Annual Hawaii International Conference on System Sciences, 2003, IEEE, 2003.

[55] A. Motamedi, M. Fotuhi-Firuzabad, H. Zareipour, Optimum simultaneous clearing of energy and spinning reserve markets using cost/benefit analysis, in: 2008 IEEE Power and Energy Society General Meeting - Conversion and Delivery of Electrical Energy in the 21st Century, IEEE, 2008: pp. 1-7.

[56] K. Pal, M. Pandit, L. Srivastava, Joint energy and reserve dispatch in a multi-area competitive market using time-varying differential evolution, International Journal of Engineering, Science and Technology. 3 (2011). 
P. González, J. Villar, C.A. Díaz, F.A. Campos. Joint energy and reserve markets: current implementations and modeling

trends. Electric Power Systems Research. vol. 109, pp. 101-111, April 2014. JCR 1.749 (2014), 2.688 (2016).

[57] Yufeng Lin, Jin Zhong, Energy and reserve dispatch in the integrated electricity market with sectional price offers, in: Transmission and Distribution Conference and Exposition, 2008. T\&\#x00026;D. IEEE/PES, IEEE, 2008: pp. 1-6.

[58] A.F. Daughety, ed., Cournot Oligopoly: Characterization and Applications, Cambridge University Press, 2005.

[59] Y. Jianlin, Y. Zheng, F. Donghan, An oligopolistic model considering the locational SR requirement for joint energyreserve market, European Transactions on Electrical Power. 20 (2010) 491-504.

[60] G. Bautista, V.H. Quintana, J. Aguado, An oligopolistic model for power networks: beyond the incentive of the energy market, in: Power Systems Conference and Exposition, 2004. IEEE PES, IEEE, 2004: pp. 1799- 1804 vol.3.

[61] G. Bautista, V.H. Quintana, J.A. Aguado, An Oligopolistic Model of an Integrated Market for Energy and Spinning Reserve, IEEE Transactions on Power Systems. 21 (2006) 132-142.

[62] X. Jia, M. Zhou, G. Li, Study on Conjectural Variation Based Bidding Strategy in Spinning Reserve Markets, in: Power System Technology, 2006. PowerCon 2006. International Conference on, 2006: pp. 1-5.

[63] H. Haghighat, H. Seifi, A.R. Kian, Joint energy and spinning reserve dispatch under imperfect competition, in: Power Symposium, 2008. NAPS '08. 40th North American, IEEE, 2008: pp. 1-7.

[64] J.M. Arroyo, F.D. Galiana, Energy and Reserve Pricing in Security and Network-Constrained Electricity Markets, IEEE Transactions on Power Systems. 20 (2005) 634-643.

[65] N. Amjady, J. Aghaei, H.A. Shayanfar, Stochastic Multiobjective Market Clearing of Joint Energy and Reserves Auctions Ensuring Power System Security, IEEE Transactions on Power Systems. 24 (2009) 1841-1854.

[66] Jianxue Wang, Xifan Wang, Yang Wu, Operating reserve model in the power market, IEEE Transactions on Power Systems. 20 (2005) 223-229.

[67] Jing Wang, N.E. Redondo, F.D. Galiana, Demand-side reserve offers in joint energy/reserve electricity markets, IEEE Transactions on Power Systems. 18 (2003) 1300- 1306.

[68] V. Siriariyaporn, M. Robinson, Co-optimization of energy and operating reserve in real-time electricity markets, in: Third International Conference on Electric Utility Deregulation and Restructuring and Power Technologies, 2008. DRPT 2008, IEEE, 2008: pp. 577-582.

[69] Tong Wu, M. Rothleder, Z. Alaywan, A.D. Papalexopoulos, Pricing energy and ancillary services in integrated market systems by an optimal power flow, IEEE Transactions on Power Systems. 19 (2004) 339- 347.

[70] K.W. Cheung, P. Shamsollahi, D. Sun, J. Milligan, M. Potishnak, Energy and ancillary service dispatch for the interim ISO New England electricity market, in: Power Industry Computer Applications, 1999. PICA '99. Proceedings of the 21 st 1999 IEEE International Conference, IEEE, 1999: pp. 47-53.

[71] G.L. Doorman, B. Nygreen, An integrated model for market pricing of energy and ancillary services, Electric Power Systems Research. 61 (2002) 169-177.

[72] F. Stacke, P. Cuervo, A Combined Pool/Bilateral/Reserve Electricity Market Operating Under Pay-as-Bid Pricing, IEEE Transactions on Power Systems. 23 (2008) 1601-1610.

[73] Zuyi Li, M. Shahidehpour, Security-constrained unit commitment for simultaneous clearing of energy and ancillary services markets, IEEE Transactions on Power Systems. 20 (2005) 1079- 1088.

[74] D. Gan, C. Shen, A price competition model for power and reserve market auctions, Electric Power Systems Research. 70 (2004) 187-193.

[75] H. Jiang, S. Zhang, Z. Hu, Y. Song, Y. Chiwei, Robust optimization method for unit commitment with network losses considering wind uncertainties, in: 2012 IEEE Power and Energy Society General Meeting, 2012: pp. 1-5.

[76] S.G. Kim, LMP as Market Signal for Reserve Supply in Energy and Reserve Integrated Market, in: Power Systems Conference and Exposition, 2006. PSCE '06. 2006 IEEE PES, 2006: pp. 896-900.

[77] T.J. Overbye, X. Cheng, Y. Sun, A comparison of the AC and DC power flow models for LMP calculations, in: Proceedings of the 37th Annual Hawaii International Conference on System Sciences, 2004, 2004: p. 9 pp.

[78] A. Ramos, S. Cerisola, J.M. Latorre, R. Bellido, A. Perea, E. Lopez, A Decision Support Model for Weekly Operation of Hydrothermal Systems by Stochastic Nonlinear Optimization, in: M. Bertocchi, G. Consigli, M.A.H.A.H. Dempster (Eds.), Stochastic Optimization Methods in Finance and Energy, Springer New York, 2011: pp. 143-161.

[79] A. Baillo, M. Ventosa, M. Rivier, A. Ramos, Optimal offering strategies for generation companies operating in electricity spot markets, Power Systems, IEEE Transactions on. 19 (2004) $745-753$.

[80] L. Wu, M. Shahidehpour, Z. Li, GENCO's Risk-Constrained Hydrothermal Scheduling, IEEE Transactions on Power Systems. 23 (2008) $1847-1858$.

[81] M. Olsson, L. Soder, Hydropower planning including trade-off between energy and reserve markets, in: Power Tech Conference Proceedings, 2003 IEEE Bologna, IEEE, 2003.

[82] E. Ni, P.B. Luh, S. Rourke, Optimal integrated generation bidding and scheduling with risk management under a deregulated power market, IEEE Transactions on Power Systems. 19 (2004) 600-609.

[83] M.M. Ahmed, M.R.A. Ghani, I. Hassan, Optimizing hydrothermal coordination scheduling for large scale power, in: International Conference on Power System Technology, 2002. Proceedings. PowerCon 2002, 2002: pp. 195 - 200 vol.1.

[84] M.P. Nowak, W. Römisch, Stochastic Lagrangian Relaxation Applied to Power Scheduling in a Hydro-Thermal System under Uncertainty, Annals of Operations Research. 100 (2000) 251-272. 
P. González, J. Villar, C.A. Díaz, F.A. Campos. Joint energy and reserve markets: current implementations and modeling trends. Electric Power Systems Research. vol. 109, pp. 101-111, April 2014. JCR 1.749 (2014), 2.688 (2016).

[85] D. Qiang, Z. Jing-yang, P. Yi, L. Qiang, H. Bin, L. Xiao-lei, et al., Coordinative Optimization Model Based on MILP for Hydrothermal Power System, in: Power and Energy Engineering Conference (APPEEC), 2012 Asia-Pacific, 2012: pp. 1 5.

[86] G.W. Chang, M. Aganagic, J.G. Waight, J. Medina, T. Burton, S. Reeves, et al., Experiences with mixed integer linear programming based approaches on short-term hydro scheduling, IEEE Transactions on Power Systems. 16 (2001) 743 749 .

[87] C.-A. Li, A.J. Svoboda, C.-L. Tseng, R.B. Johnson, E. Hsu, Hydro unit commitment in hydro-thermal optimization, IEEE Transactions on Power Systems. 12 (1997) $764-769$.

[88] L. Soder, Reserve margin planning in a wind-hydro-thermal power system, IEEE Transactions on Power Systems. 8 (1993) $564-571$.

[89] H. Chen, J. Wang, Y. Zhang, Economic Dispatch of Hydro-Thermal Power System with Large-Scale Wind Power Penetration, in: Power and Energy Engineering Conference (APPEEC), 2012 Asia-Pacific, 2012: pp. $1-4$.

[90] F.J. Heredia, N. Nabona, Optimum short-term hydrothermal scheduling with spinning reserve through network flows, IEEE Transactions on Power Systems. 10 (1995) 1642-1651.

[91] E. Gil, J. Bustos, H. Rudnick, Short-term hydrothermal generation scheduling model using a genetic algorithm, IEEE Transactions on Power Systems. 18 (2003) $1256-1264$.

[92] C.E. Zoumas, A.G. Bakirtzis, J.B. Theocharis, V. Petridis, A genetic algorithm solution approach to the hydrothermal coordination problem, IEEE Transactions on Power Systems. 19 (2004) 1356 - 1364.

[93] A.G. Bakirtzis, Joint energy and reserve dispatch in a competitive pool using Lagrangian relaxation, IEEE Power Engineering Review. 18 (1998) 60-62.

[94] J. Richter, A Unique Competitive Equilibrium on Interdependent Spot Electricity and Reserve Capacity Markets, EWI Working Papers. (2011).

[95] S. Hongxing, Z. Jianbin, Y. Lin, L. Jie, Generators' Reserve Equilibrium Relationship Based on Game Theory and Opportunity Cost, in: Power and Energy Engineering Conference (APPEEC), 2010 Asia-Pacific, 2010: pp. 1-6.

[96] C.A. Díaz, J. Villar, F.A. Campos, J. Reneses, Electricity market equilibrium based on conjectural variations, Electric Power Systems Research. 80 (2010) 1572-1579.

[97] J.I. Pérez-Arriaga, M. Rivier, C. Batlle, C. Vázquez, P. Rodilla, White paper on the reform of the regulatory framework of Spain's electricity generation, Ministerio de Industria y Comercio of Spain, 2005.

[98] Y. Liu, F.F. Wu, Impacts of Network Constraints on Electricity Market Equilibrium, IEEE Transactions on Power Systems. 22 (2007) 126-135.

[99] C.A. Díaz, J. Villar, F.A. Campos, M.Á. Rodríguez, A new algorithm to compute conjectured supply function equilibrium in electricity markets, Electric Power Systems Research. 81 (2011) 384-392. 